\title{
Relationship between Chronic Low Back Pain and Risk of Fall and Depression among Community Dwelling Older Adults
}

\author{
Nawara Kirallah Abd El Fatah Abd El Ghany, Demonstrator \\ Gerontological Nursing, Faculty of Nursing, Damanhour University \\ Somaya Abd El Moneim Bader El-Din El Shazly, Professor \\ Gerontological Nursing, Faculty of Nursing, Alexandria University \\ Hanaa Abou El-soued Hussein Ahmed, Lecturer \\ Gerontological Nursing, Faculty of Nursing, Alexandria University \\ Magda Mahmoud Mohamed Algameel, Lecturer \\ Gerontological Nursing, Faculty of Nursing, Damanhour University
}

\begin{abstract}
Chronic low back pain (CLBP) is a serious health problem affecting more than $50 \%$ of community-dwelling older adults worldwide and its prevalence increases with advanced age. It has a significant effect on all aspects of older adults' life. It affects the physical status of older adults causing activity limitation, loss of independence, and increased risk for fall and depression. Objective: Determine the relationship between chronic low back Pain and risk of fall and depression among community dwelling older adults. Setting: The outpatient clinic of the Physical Medicine, Rheumatology and Rehabilitation Department; at the Main University Hospital, Alexandria, Egypt. Subjects: A convenience sample of 120 older adults with chronic low back pain was recruited. Tools: Four tools were used for data collection: 1) Socio-demographic Characteristics and Clinical Data of the Older Adults with CLBP Structured Interview Schedule, 2) Colored Analogue Pain Assessment Scale, 3) Fall Risk Assessment Scale for Older People, and4) Beck Depression Inventory. Results: A high statistically significant relationship between the severity of CLBP and the degree of fall risk and the severity of depression among the study subjects, as well as a significant association was found between severity of depression and the risk for fall among them. Conclusion: CLBP is significantly associated with increased risk of fall and depression; this risk is positively correlated with the severity of pain. Recommendations: Periodic follow up for older adults with CLBP especially those who are at risk for falls and depression to improve their physical and psycho-social status and prevent pain recurrence.
\end{abstract}

Keywords: Chronic low back pain; Older adults; Community dwelling; Falls; Depression; Gerontological nurse.

\section{Introduction}

Chronic Low Back Pain (CLBP) is defined as pain and discomfort below the costal margin and above the inferior gluteal folds, with or without referred leg pain that lasts more than 3 months ${ }^{(1)}$.

CLBP among older adults is considered one of the most common diagnostically complex, disabling, and therapeutically challenging disease of all chronic pain disorders ${ }^{(2)}$. This is because it affects the patients' functional abilities leading to loss of independence and longterm disability. It can also limit their social and recreational activities. Moreover, it leads to sleep disturbance, Irritability, reduced appetite and severe psychological, physiological and social consequences ${ }^{(3,4)}$.

CLBP is characterized by aching, stabbing, burning, sharp, and well-defined or vague sensation. The intensity of the pain may range from mild to severe. The pain usually begins suddenly as acute pain and progresses to chronic pain in elders ${ }^{(5)}$. It may restrict all daily activities. Therefore, it 
is called "disabling, persistent or restricting CLBP" $^{\prime \prime 6,7)}$.

CLBP is one of the most prevalent chronic musculoskeletal conditions in older adults. In USA, Kelley et al. (2017) reported that CLBP is the second common cause of disabilities affecting more than 25 million elders $^{(8)}$. In Egypt (2016), the prevalence of CLBP among community dwelling older adults attending the Physical Medicine, Rheumatology, and Rehabilitation Department of Alexandria Main University Hospital was estimated to be about $71 \%{ }^{(9)}$. A study done by Disoky et al. (2015) in Ismailia, in Egypt, indicated that the prevalence of CLBP among older adults was $48 \%{ }^{(10)}$.

Older adults have numerous risk factors for developing CLBP. Aging is the first and most important one. Inevitable changes are brought about to people as they grow old ${ }^{(11)}$. Other important risk factors include sedentary life style, postural changes, and inappropriate use of body mechanics, obesity, caffeine consumption, and smoking ${ }^{(12)}$. CLBP can be aggravated by medical conditions; some of them are spinalrelated problems such as osteoporotic vertebral fractures, spinal osteoarthritis, spinal stenosis, spinal infection, spinal deformities, and tumor or cancer of the spine and the other are related to non-spinal problems as diabetes mellitus, hypertension, musculoskeletal disorders, respiratory diseases and other visceral diseases ${ }^{(12,13)}$.

Older adults with CLBP are at greater risk for falls. This is because CLBP contributes to functional decline, muscle weakness, balance or posture alterations and mobility limitations ${ }^{(14,15)}$. Older adults with CLBP may limit their activities of daily living and instrumental activities because activity exacerbates the pain or because of fear of falling ${ }^{(16)}$. Fall is associated with higher morbidity and mortality and is considered one of the ten leading causes of death in older adults ${ }^{(17)}$.
CLBP does not only affect the physical status and increases fall risk among older adults, but it also impairs their psychological wellbeing; the pain often makes it difficult to sleep, leading to fatigue and irritability during the day. Older adults with CLBP have difficulty with most movement and they often move slowly and carefully, spending most of time at their homes away from others resulting in social isolation and lack of enjoyable activities. Sexual activity is often affected by CLBP and this causes more stress in the patientpartner relationship and may result in depression $^{(18)}$.

The relationship between CLBP and depression may be bidirectional. This is because the presence of persistent pain can increase the risk for depression; depressive symptoms may also worsen both the severity of pain and disability caused by CLBP among older adults and vice versa ${ }^{(19,20)}$.

The gerontological nurse has greater responsibility toward older adults with CLBP. He/or she plays an important role in their assessment in order to early identify those at risk for falls and depression. This helps to apply effective nursing care to relieve pain, prevent falls and depression, as well to help in restoring lost physical abilities, and maintain sense of well-being and self- esteem. The nurse is also responsible for monitoring the patient's compliance and response to prescribed treatment modalities ${ }^{(21,22)}$.

Although several studies were conducted on chronic low back pain, there are scarce literatures which focus on the association of these three variables; CLBP, fall, and depression among community dwelling older adults.

\section{Aim of the Study}

The aim of the study is to determine the relationship between chronic low back pain and risk of fall and depression among community dwelling older adults. 


\section{Research Question}

What is the relationship between chronic low back pain and risk of fall and depression among community dwelling older adults?

\section{Materials and Method}

\section{Materials}

Design: The study followed a descriptive correlational research design.

Setting: The study was carried out at the outpatient clinic affiliated to the Physical Medicine, Rheumatology, and Rehabilitation Department; at the Main University Hospital, Alexandria, Egypt. This clinic works 6 dayslweek from Saturday to Thursday from 8.30 am to 12 midday. The estimated number of older adults reporting chronic low back pain and attending this clinic ranges from 90 to 100 per month ${ }^{(23)}$.

Subjects: The study included a convenience sample of 120 older adults diagnosed with chronic low back pain, attending the previously mentioned clinic for follow up of their therapeutic regimen, available during the period of data collection, and fulfilling the following criteria:

- Aged 60years and more.

- Have chronic low back pain persisting for more than 3 months ${ }^{(1)}$.

- Able to communicate effectively.

- Free from back surgery or traumatic injuries and neurological disorders; such as stroke and Parkinson disease.

The sample size was estimated using the EPI info 7.0 program based on these parameters; population size: 300 over three months, expected frequency: $50 \%$, acceptable error: $10 \%$, confidence coefficient: $99 \%$, the minimum sample size was 107.

Tools: In order to fulfill the objective of the study, four tools were used:

\footnotetext{
Tool I: $\quad$ Socio-demographic Characteristics and Clinical Data of the Older Adults with chronic Low Back Pain Structured Interview Schedule
}

It was designed by the researchers based on review of the relevant literature and covered three parts:

Part 1: Socio-demographic characteristics of the older adults such as age, sex, marital status, level of education, occupation before retirement, place of residence and monthly income.

Part 2: Health profile of the elders includes systemic medical disorders and medications consumed by elders.

Part 3: Assessment of CLBP including site of pain, radiation site, type of pain, duration of pain, pattern of pain, aggravating and alleviating factors.

\section{Tool II: Colored Analogue Pain Assessment Scale (CAS)}

This tool was developed by McGrath et al. $(1996)^{(24)}$, the CAS is used to measure the severity of pain. In this study, it was used in order to assess the severity of CLBP in older adults. The CAS scale was translated into Arabic language and proved to be valid and reliable by Tannous $(2015)^{(25)}, \mathrm{r}=0.97$. The Arabic version of the scale was used in the present study.

The CAS resembles a ruler, with one side showing a wedge-shaped figure filled with color that gradually progresses from white to red and the other side showing corresponding numerical rating from 1 to 10 $\mathrm{cm}$ where zero $(0)$ indicates no pain and ten (10) indicates the worst pain. Selecting the appropriate scale position takes place by sliding a horizontal marker from the bottom (no pain) to the top (maximum pain). The total score of the CAS scale is 10 and classified as follow; 0 no pain, 1-3 mild pain, 4-6 moderate pain, and 7-10 severe pain.

\section{Tool III: Fall Risk Assessment Scale for Older People (FRAS)}

This scale was developed by Cannard $(1989)^{(26)}$, the FRAS is used to determine the risk factors of falls among older people. It was used in this study to assess the risk factors for falls among older adults with 
CLBP and it includes sex, age, gait, mobility, fall history, sensory deficit, medications and medical history. This scale was translated into Arabic language by Algameel (2013) ${ }^{(27)}$ and proved to be valid and reliable, $r=0.92$. The Arabic version of the scale was used in the present study. The total score of the scale is 19 and classified as follow; 3-8 low risk, 9-12 moderate risk, and $\geq 13$ high risk.

\section{Tool IV: Beck Depression $\underline{\text { Inventory (BDI) }}$}

It was developed by Beck $(1996)^{(28)}$. It consists of 21 multiple-choice questions, self-reported inventory used in order to assess the severity of depression. BDI was translated into Arabic language by the researchers and the Arabic version was used in the present study.

Items of BDI are rated on a 4-point scale ranging from 0 to 3 based on severity of each item. Items 1 to 15 assess symptoms that are psychological in nature such as sadness, pessimism, sense of failure, selfdissatisfaction, guilt, punishment, selfdislike, self-accusation, suicidal ideas, crying, irritability, social withdrawal, decision making ability, body image, and work difficulties.

Items 16 to 21 assess more physical symptoms such as insomnia, fatigue, appetite loss, weight loss, health preoccupation, and loss of libido. The total score of the scale is 63 and classified as follow; 0-10 no depression, 11-16 mild depression, 17-20 borderline clinical depression, 21-30 moderate depression, 3140 severe depression, and >40 extreme depression.

\section{Method}

- An official letter was issued from the Faculty of Nursing, Alexandria University and forwarded to the responsible authorities to obtain their approval to collect the data, and were informed about the purpose of the study, date and time of starting data collection.

- Tool I was designed by the researchers based on review of related literature to assess the sociodemographic and clinical data of the study subjects.

- The Arabic versions of tool II and tool III were used in the present study.

- Tool IV was translated into Arabic language by the researchers and validated by juries of (7) experts in the field. Their suggestions and recommendations were taken into consideration. Cronbach's coefficient alpha test was used to ascertain the reliability of this tool $\mathrm{r}=0.93$.

- A pilot study was carried out on 11 older adults with CLBP who fulfilled the inclusion criteria and selected from the study setting. They were not included in the study sample. It was done in order to determine the relevance, clarity and applicability of the tools, test wording of the questions and estimate the time required for the interview. Based on the obtained results, the necessary modifications were done.

- Older adults who fulfilled the inclusion criteria were interviewed individually by the researchers in the waiting area of the clinic. The researchers used to go to the study setting 3 days/week from 8.30 am to 12 midday. Around four to five elders were interviewed/day.

- The researchers applied the study tools on the subjects before receiving the prescribed rehabilitation session in order to avoid the effect of this session on the severity of CLBP and limit the possibility of biased results.

- Each interview took approximately 30-45 minutes, depending on the participants' level of understanding and cooperation. 
- Collection of data covered a period of four months, from the beginning of November 2017 till the end of February 2018.

\section{Ethical considerations:}

Informed witness consent was obtained from each participant after clarification of the study purpose. Participants were assured that their responses will be kept anonymous. Also, confidentiality of the collected data was maintained. Each participant was informed that participation in the study is voluntary and he can withdraw at any time.

\section{Statistical Analysis}

The collected data were coded and analyzed using PC with the Statistical Package for Social Sciences (SPSS) software version 23. Tabulated frequency and percentages were calculated. Descriptive statistics as frequency, distribution, mean, and standard deviation were used to describe different characteristics. The Chi-square test, Fisher Exact Test and Monte Carlo test were used for testing relationship between categorical variables. Significant difference was considered if $\mathrm{p} \leq 0.05$.

\section{Results}

The age of the study subjects ranged from 60 to 86 years with a mean of $71.98 \pm 6.65$ years, $55.0 \%$ were females, $42.5 \%$ were married, and $40.0 \%$ illiterate. $29.2 \%$ of the study subjects were housewives, $25.8 \%$ both manual and technical workers i.e. Farmer, carpenter, tailor, builder, or driver, $25.8 \%$, and $19.2 \%$ were employees or had free business respectively.

Table (1) shows that all study subjects $(100.0 \%)$ reported that they suffered from one or more chronic systemic disorders; musculoskeletal disorders such as osteoarthritis, rheumatoid arthritis, and osteoporosis were the most common disorders $(76.5 \%)$ among the study subjects. This is followed by $66.4 \%$ suffered from cardiovascular diseases as hypertension, and
$44.5 \%$ reported having diabetes mellitus. As for genitourinary disorders such as urinary tract infection, prostatitis, and kidney stones, these were reported by $39.5 \%$. Gastrointestinal disorders which involve chronic constipation and cholecystolithiasis were reported by one third $(33.6 \%)$ of the study subjects.

Analgesics and anti-inflammatory drugs were consumed by $74.2 \%$ of the study subjects followed by cardiac drugs $(65.8 \%)$, hypoglycemic agents (44.2\%), renal drugs (39.2\%), and GIT drugs (30.8\%). Hypnotics or anxiolytics and respiratory drugs were consumed by $24.2 \%$ and $19.2 \%$ respectively.

Table (2) describes the characteristics of CLBP among the study subjects. The severity of CLBP fluctuated between severe in nearly one half $(49.2 \%)$ of the study subjects to moderate in $45.8 \%$. More than two thirds $(70.0 \%)$ of the studied elders experienced pain in the lower area of the back (lumbar and sacroiliac regions) radiating to different sites such as all the back, leg, foot, thighs, and neck in about $63.3 \%$ of them, more than one half $(51.7 \%)$ of the study subjects reported that LBP lasting for $\geq 30$ minutes and they described their pain as needle-like, crushing, burning, stabbing, and sharp which amounted $30.8 \%$, $25.8 \%, 16.7 \%, \quad 15.0 \%$ and $11.7 \%$ respectively, and $60.0 \%$ had continuous CLBP.

Moreover, the most common aggravating factor of pain was improper body alignment $(80.8 \%)$, followed by sitting or standing for long period, excessive effort, stress, lifting heavy weights, and constipation which constituted $74.2 \%, 52.5 \%, 45 \%, 29.2 \%$, and $22.5 \%$ respectively.

On the other hand analgesics were the first alleviating measure $(72.5 \%)$ used by the study subjects, followed by physiotherapy sessions, warm shower, rest, sleep, and back massage which constituted $68.3 \%, 56.7 \%$, $40.8 \%, 17.5 \%$, and $8.3 \%$ respectively.

Figure (1) clarifies that more than one half of the study subjects $(52.5 \%)$ had 
moderate risk for fall, and the rest $(25.8 \%$, $21.7 \%$ ) were between mild to high risk respectively.

Figure (2) illustrates that the vast majority $(94.2 \%)$ of the study subjects reported depressive symptoms; more than one third $(35.0 \%)$ reported moderate depression, followed by $16.7 \%$ had mild depression, $15.8 \%$ had borderline depression, and the rest had either severe or extreme depression which constituted $14.2 \%$ and $12.5 \%$ respectively.

Table (3) revealed a positive highly statistically significant association between the severity of CLBP and the degree of fall risk $(\mathrm{FET}=13.215, \mathrm{p}=0.001 *)$. For more clarification; when the severity of CLBP increases, the risk of fall increases.

Table (4) indicates that the severity of CLBP was linked with the severity of depression thus, the relationship is highly statistically significant $\quad($ FET $=27.468$, $\mathrm{p}=0.000 *$ ).

Table (5) reflects the relationship between the severity of depression and the degree of fall risk among the study subjects with CLBP. According to this table, there is a positive significant correlation between the severity of depression and the degree of fall risk $\left(\mathrm{FET}=27.468, \mathrm{p}=0.000^{*}\right)$.

\section{Discussion}

Older adults' daily functioning can be obstructed by CLBP which often leads to falls, severe physical disability as well as high incidence of depression and affects all aspects of older adults' life ${ }^{(29,30)}$. The study aimed to determine the relationship between CLBP and risk of fall and depression among community dwelling older adults.

The results of the current study revealed that all of the study subjects were at risk for fall where more than one half were at moderate risk for fall, the rest were between mild to high risk (figure 1). This is may be due to neuromuscular effects of pain that may interfere with balance control. This will result in loss of balance and altered postural responses. Also, older adults with CLBP often avoid physical activities; this may result in muscle weakness and functional decline which predispose them for greater risk for fall. Moreover, both fear of falling and avoidance of activity because of pain are associated with increased fall risk. As well, psychological responses to CLBP are another possible reason.

Since decreased physical functions have an impact on psycho-social health, it reduces the quality of mental well-being that increases risk of falls. Additionally, long term use of analgesics and antiinflammatory drugs to relieve CLBP may affect elders' cognition causing drowsiness, and may lead to fall ${ }^{(31)}$. In this respect, the present study reflected that these drugs were the first relieving measures of CLBP used by nearly three quarters of the study subjects (table 1).

The result of the current study revealed a highly statistically significant association between CLBP and risk of fall; when the severity of CLBP increases, the risk of fall increases (table 3). This supports the results of other studies in Japan $(2017)^{(32)}$, USA $(2016)^{(33)}$, and Brazil $(2016)^{(34)}$.

The results of the present study reflected a highly statistically significant association of the severity of CLBP and a number of depressive symptoms among the study subjects such as social withdrawal, self-dissatisfaction, and sense of failure, moreover, feeling of guilt, feeling of sadness, pessimism, self-dislike, selfaccusation, irritability, insomnia, fatigue, poor appetite, poor body image, crying, and loss of libido (figure 2 and table 4 ). This is due to limitations in physical functioning resulting from CLBP because of pain which Lead to fear of falling among older adults. This has an impact on their psycho-social status such as depression and social isolation $^{(30,35)}$. This finding also may be due to the fact that CLBP can make older adults feel helpless and disabled. As a consequence, they have less motivation to do their best performance in activities 
resulting in loss of independence and poor perceived self-image. In addition, the high prevalence of comorbid conditions among the vast majority $(99.2 \%)$ of the study subjects may add more stressors and may cause depression because of poor perception of their health (table 1). The same was reported by Marcic et al. (2014) ${ }^{(36)}$ and Tetsunaga et al. (2013) ${ }^{(37)}$ added that the majority of CLBP patients had depression and the severity of depression is correlated with the severity of pain. Moreover, Jiménez et al. in Spain (2012) $)^{(38)}$ postulated that the incidence of depressive symptoms are higher in community-dwelling older people with CLBP and concluded that the more severe the back pain is the more likely to experience depression. On the contrary, Fernandez et al. (2017) ${ }^{(39)}$ in Australia found no significant relation between CLBP and depression.

The finding of the present study also indicated an association between risk of fall and depression among older adults with CLBP (table 5). This may be due to the negative consequences of depressive symptoms on sensory, cognitive, and motor functions of older adults ${ }^{(40)}$. Furthermore, both risk of fall and depression are associated with CLBP especially if this pain is severe and with specific characteristics such as recurrent and persistent, radiating to different sites of the body result in increasing suffering and limitation of their activities and lasts for more than thirty minutes (table 2).

Additionally, the intensity of CLBP is described by the study subjects as difficult to tolerate, needle-like, burning, crushing, stabbing, and sharp. Moreover, older adults usually have improper body alignment because of age-related changes in their posture which aggravates and impairs their physical and psychological condition ${ }^{(41)}$. The same was reported by Ramzy $(2013)^{(5)}$ in Alexandria, Egypt, and Turcu et al. $(2015)^{(42)}$.

\section{Conclusion}

From the findings of the present study it can be concluded that CLBP has a significant relationship with the physical and psychological status of the studied older adults. Older adults who reported CLBP are at risk for falls and depression. This risk is positively correlated with the severity of pain.

\section{Recommendations}

Based on the findings of the present study, the following recommendations are suggested:

- The gerontological nurses should develop and conduct an educational program for older adults with CLBP and their families related to selfmanagement of pain which include exercises, relaxation techniques, good body mechanics, and participation in social and recreational activities. These help older adults to develop a sense of control over their pain, prevent pain related falls and depression, empower their functional abilities, and maintain high quality of life.

- Screening of balance, motor function, and fall risk of older adults with CLBP should be an integral part of the gerontological nurses' regular assessment and evaluation, and should be incorporated into the routine care of those patients. This will help to identify functional problems and intervene as early as possible.

- Provide health teaching for older adults with CLBP and their caregivers related to home environment modifications in order to apply measures to overcome hazards and decrease risk for falls. 


\section{The future researches in this field could include:}

- More studies are needed to determine the effect of nursing strategies on improving physical and psychological function among older adults with CLBP.

\section{Acknowledgement}

The authors are thankful to all elders agreed to participate in this study. Deepest gratitude also goes to the head of Physical Medicine, Rheumatology and Rehabilitation Department; at the Main University Hospital, Alexandria, Egypt, for his approval to conduct the study.

Table (1): Distribution of the study subjects according to their health profile

\begin{tabular}{||l|c|c||}
\hline \multirow{2}{*}{ Health profile } & \multicolumn{2}{|c||}{ The studied subjects (no. = 120) } \\
\cline { 2 - 3 } & no. & \% \\
\hline Presence of systemic disorders: \# & & 76.5 \\
Musculoskeletal disorders & 79 & 66.4 \\
Cardiovascular disorders & 53 & 44.5 \\
Endocrine disorder (DM) & 47 & 39.5 \\
Genitourinary disorders & 40 & 33.6 \\
Gastrointestinal disorders & 23 & 19.3 \\
Respiratory disorders & 3 & 2.5 \\
Tumor/ Cancer & & 74.2 \\
\hline Type of current medications consumed: \# & 89 & 65.8 \\
Analgesics\& anti-inflammatory drugs & 79 & 44.2 \\
Cardiovascular drugs & 53 & 39.2 \\
Hypoglycemic agents & 47 & 30.8 \\
Renal drugs & 37 & 24.2 \\
GIT drugs & 29 & 19.2 \\
Hypnotics/ anxiolytics & 23 & 14.2 \\
Respiratory drugs & 17 & \\
Others & & \\
\hline \hline
\end{tabular}

\# Multiple responses were given 
Table (2): Distribution of the study subjects according to their CLBP characteristics

\begin{tabular}{|c|c|c|}
\hline \multirow{2}{*}{ CLBP characteristics } & \multicolumn{2}{|c|}{ The studied subjects $($ no. $=120)$} \\
\hline & no. & $\%$ \\
\hline $\begin{array}{l}\text { Site of pain: } \\
\text { Lower area of the back } \\
\text { Center of buttocks }\end{array}$ & $\begin{array}{l}84 \\
36\end{array}$ & $\begin{array}{l}70.0 \\
30.0\end{array}$ \\
\hline $\begin{array}{l}\text { Radiation's site: } \\
\text { Yes } \\
\text { All back } \\
\text { Leg } \\
\text { Foot } \\
\text { Thigh } \\
\text { Neck } \\
\text { NO } \\
\end{array}$ & $\begin{array}{l}76 \\
24 \\
20 \\
11 \\
11 \\
10 \\
\mathbf{4 4}\end{array}$ & $\begin{array}{l}\mathbf{6 3 . 3} \\
31.6 \\
26.3 \\
14.5 \\
14.5 \\
13.1 \\
\mathbf{3 6 . 7}\end{array}$ \\
\hline $\begin{array}{l}\text { Duration: } \\
10<15 \mathrm{~min} \\
15-30 \mathrm{~min} \\
>30 \mathrm{~min}\end{array}$ & $\begin{array}{l}12 \\
46 \\
62 \\
\end{array}$ & $\begin{array}{l}10.0 \\
38.3 \\
51.7\end{array}$ \\
\hline $\begin{array}{l}\text { Type of pain: } \\
\text { Needle- like } \\
\text { Crushing } \\
\text { Burning } \\
\text { Stabbing } \\
\text { Sharp } \\
\end{array}$ & $\begin{array}{l}37 \\
31 \\
20 \\
18 \\
14\end{array}$ & $\begin{array}{l}30.8 \\
25.8 \\
16.7 \\
15.0 \\
11.7 \\
\end{array}$ \\
\hline $\begin{array}{l}\text { Pattern: } \\
\text { Continuous } \\
\text { Intermittent }\end{array}$ & $\begin{array}{l}72 \\
48 \\
\end{array}$ & $\begin{array}{l}60.0 \\
40.0 \\
\end{array}$ \\
\hline $\begin{array}{l}\text { Severity: } \\
\text { Sever pain } \\
\text { Moderate pain } \\
\text { Mild pain }\end{array}$ & $\begin{array}{c}59 \\
55 \\
6 \\
\end{array}$ & $\begin{array}{c}49.2 \\
45.8 \\
5.0\end{array}$ \\
\hline $\begin{array}{l}\text { Aggravating factors: \# } \\
\text { Improper body alignment } \\
\text { Standing/sitting for long period } \\
\text { Strenuous effort } \\
\text { Stress } \\
\text { Lifting heavy weights } \\
\text { Constipation }\end{array}$ & $\begin{array}{l}97 \\
89 \\
63 \\
54 \\
35 \\
27\end{array}$ & $\begin{array}{l}80.8 \\
74.2 \\
52.5 \\
45.0 \\
29.2 \\
22.5 \\
\end{array}$ \\
\hline $\begin{array}{l}\text { Alleviating factors: \# } \\
\text { Analgesics } \\
\text { Physiotherapy sessions } \\
\text { Warm shower } \\
\text { Rest } \\
\text { Sleep } \\
\text { Back massage }\end{array}$ & $\begin{array}{l}87 \\
82 \\
68 \\
49 \\
21 \\
10\end{array}$ & $\begin{array}{c}72.5 \\
68.3 \\
56.7 \\
40.8 \\
17.5 \\
8.3\end{array}$ \\
\hline
\end{tabular}




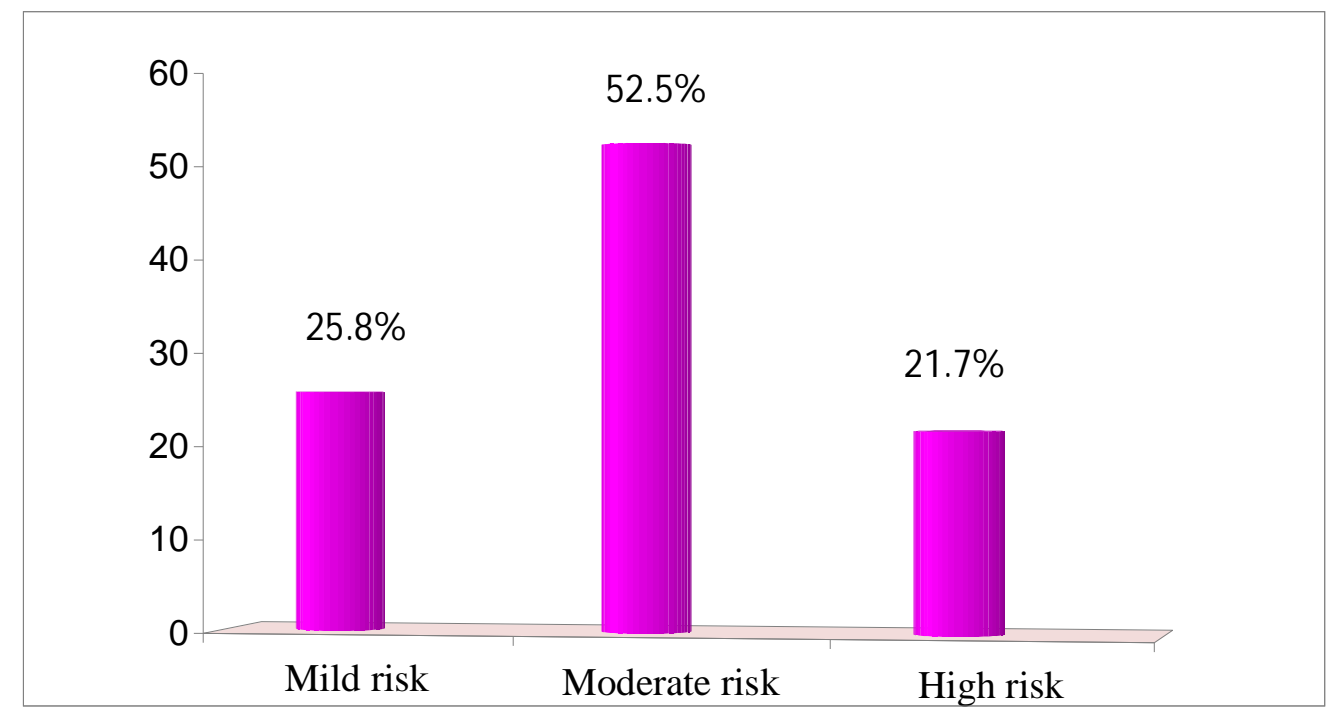

Figure (1): Distribution of the study subjects according to their risk of fall

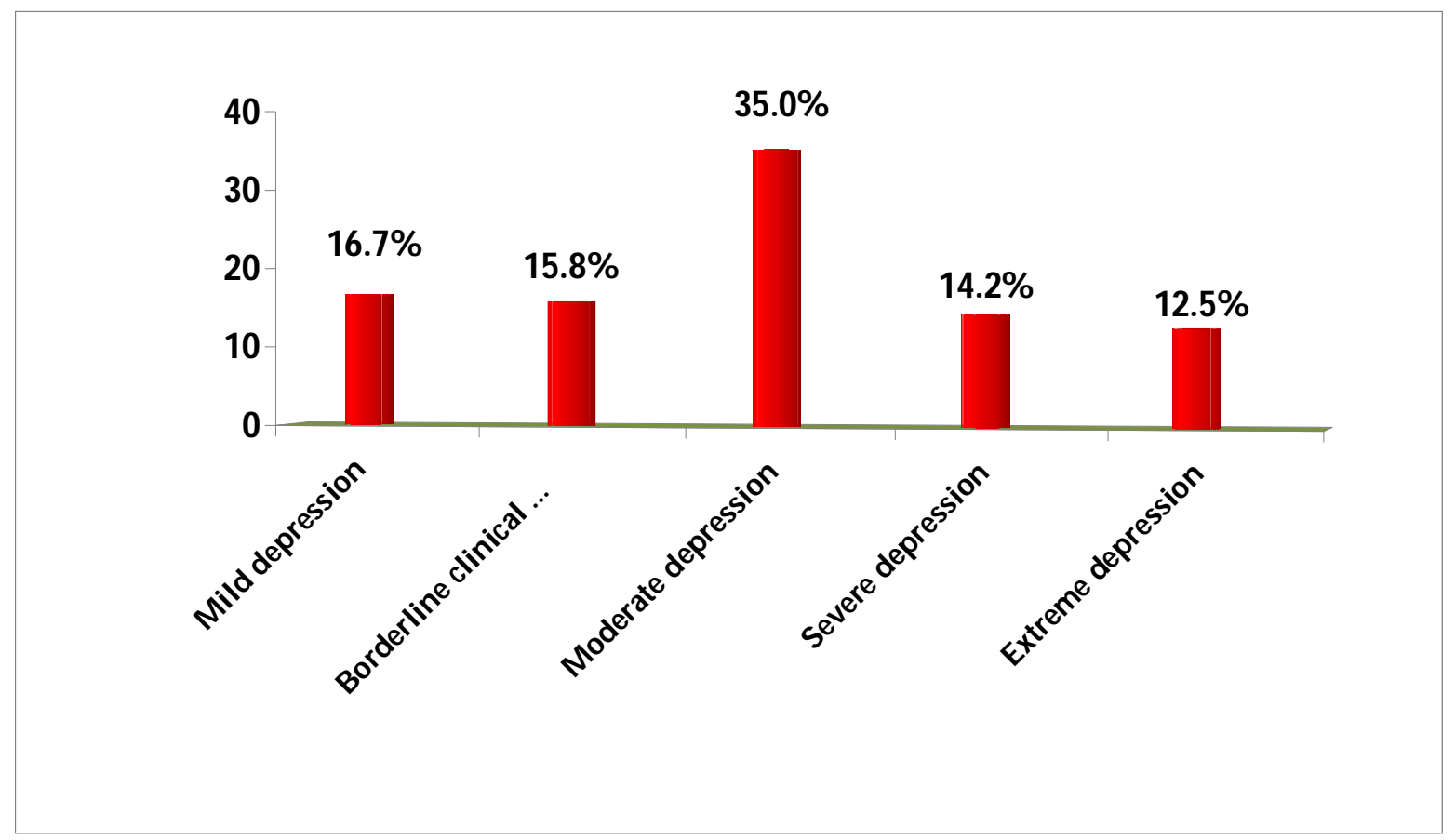

Figure (2): Distribution of the study subjects according to their severity of depression 
Table (3): Relationship between the severity CLBP and the degree of fall risk among the study subjects

\begin{tabular}{|c|c|c|c|c|c|c|c|c|c|}
\hline \multirow{3}{*}{$\begin{array}{l}\text { Severity of chronic } \\
\text { low back pain }\end{array}$} & \multicolumn{8}{|c|}{ Risk of fall } & \multirow{3}{*}{$\begin{array}{c}\text { Test of } \\
\text { significance } \\
\text { Fisher's } \\
\text { Exact Test } \\
\text { (FET) }\end{array}$} \\
\hline & \multicolumn{2}{|c|}{ Mild risk } & \multicolumn{2}{|c|}{$\begin{array}{c}\text { Moderate } \\
\text { risk }\end{array}$} & \multicolumn{2}{|c|}{ High risk } & \multicolumn{2}{|c|}{ Total } & \\
\hline & no. & $\%$ & no. & $\%$ & no. & $\%$ & no. & $\%$ & \\
\hline Mild pain $(\mathrm{no}=6)$ & 3 & 50.0 & 3 & 50.0 & 0 & 0.0 & 6 & 100.0 & \\
\hline $\begin{array}{l}\text { Moderate pain } \\
(\mathrm{no=55})\end{array}$ & 20 & 36.4 & 28 & 50.9 & 7 & 12.7 & 55 & 100.0 & FET:13.215 \\
\hline Severe pain $(n o=59)$ & 8 & 13.6 & 32 & 54.2 & 19 & 32.2 & 59 & 100.0 & $\mathrm{P}: 0.001^{*}$ \\
\hline Total $(\mathrm{no}=120)$ & 31 & 25.8 & 63 & 52.5 & 26 & 21.7 & 120 & 100.0 & \\
\hline
\end{tabular}

FET: Fisher Exact Test

* Statistically significance $P: \leq 0.05$

Table (4): Relationship between the severity of CLBP and level of depression among the study subjects

\begin{tabular}{|c|c|c|c|c|c|c|c|c|c|c|c|c|c|c|c|}
\hline \multirow{3}{*}{$\begin{array}{l}\text { Severity } \\
\text { of } \\
\text { chronic } \\
\text { low back } \\
\text { pain }\end{array}$} & \multicolumn{12}{|c|}{ Level of depression } & \multirow{2}{*}{\multicolumn{2}{|c|}{ Total }} & \multirow{3}{*}{$\begin{array}{c}\text { Test of } \\
\text { significance } \\
\text { Fisher's } \\
\text { Exact Test } \\
\text { (FET) }\end{array}$} \\
\hline & \multicolumn{2}{|c|}{$\begin{array}{c}\text { No } \\
\text { depression }\end{array}$} & \multicolumn{2}{|c|}{$\begin{array}{c}\text { Mild } \\
\text { depression }\end{array}$} & \multicolumn{2}{|c|}{ Borderline } & \multicolumn{2}{|c|}{ Moderate } & \multicolumn{2}{|c|}{ Severe } & \multicolumn{2}{|c|}{ Extreme } & & & \\
\hline & no. & $\%$ & no. & $\%$ & no. & $\%$ & no. & $\%$ & no. & $\%$ & no. & $\%$ & no. & $\%$ & \\
\hline $\begin{array}{l}\text { Mild pain } \\
(\mathrm{no}=6)\end{array}$ & 0 & 0.0 & 4 & 66.7 & 2 & 33.3 & 0 & 0.0 & 0 & 0.0 & 0 & 0.0 & 6 & 100.0 & \\
\hline $\begin{array}{l}\text { Moderate } \\
\text { pain } \\
(\text { no=55) }\end{array}$ & 6 & 10.9 & 13 & 23.6 & 7 & 12.7 & 20 & 36.4 & 6 & 10.9 & 3 & 5.5 & 55 & 100.0 & EFT.27 168 \\
\hline $\begin{array}{l}\text { Severe } \\
\text { pain } \\
(\mathrm{no}=59)\end{array}$ & 1 & 1.7 & 3 & 5.1 & 10 & 16.9 & 22 & 37.3 & 11 & 18.7 & 12 & 20.3 & 59 & 100.0 & P:0.000* \\
\hline $\begin{array}{l}\text { Total } \\
(n o=120)\end{array}$ & 7 & 5.8 & 20 & 16.7 & 19 & 15.8 & 42 & 35.0 & 17 & 14.2 & 15 & 12.5 & 120 & 100.0 & \\
\hline
\end{tabular}


Table (5): Relationship between the severity of depression and the degree of fall risk among the study subjects with CLBP

\begin{tabular}{|c|c|c|c|c|c|c|c|c|c|}
\hline \multirow{3}{*}{ Level of depression } & \multicolumn{6}{|c|}{ Risk of fall } & \multirow{2}{*}{\multicolumn{2}{|c|}{ Total }} & \multirow{3}{*}{$\begin{array}{c}\text { Test of } \\
\text { significance }\end{array}$} \\
\hline & \multicolumn{2}{|c|}{ Mild risk } & \multicolumn{2}{|c|}{ Moderate risk } & \multicolumn{2}{|c|}{ Severe risk } & & & \\
\hline & No & $\%$ & No & $\%$ & No & $\%$ & No & $\%$ & \\
\hline No depression(n=7) & 4 & 57.1 & 3 & 42.9 & 0 & 0.0 & 7 & 100.0 & \\
\hline Mild depression $(n=20)$ & 13 & 65.0 & 7 & 35.0 & 0 & 0.0 & 20 & 100.0 & \\
\hline $\begin{array}{l}\text { Borderline } \\
\text { depression }(n=19)\end{array}$ & 7 & 36.8 & 12 & 63.2 & 0 & 0.0 & 19 & 100.0 & \\
\hline $\begin{array}{l}\text { Moderate depression } \\
(\mathrm{n}=42)\end{array}$ & 7 & 16.7 & 27 & 64.3 & 8 & 19.0 & 42 & 100.0 & $\begin{array}{l}\text { FET:52.659 } \\
\text { p. }<0001^{*}\end{array}$ \\
\hline $\begin{array}{l}\text { Severe depression } \\
(n=17)\end{array}$ & 0 & 0.0 & 7 & 41.2 & 10 & 58.8 & 17 & 100.0 & \\
\hline $\begin{array}{l}\text { Extreme depression } \\
(n=15)\end{array}$ & 0 & 0.0 & 7 & 46.7 & 8 & 53.3 & 15 & 100.0 & \\
\hline Total $(n=120)$ & 31 & 25.8 & 63 & 52.5 & 26 & 21.7 & 120 & 100.0 & \\
\hline
\end{tabular}




\section{References}

1. North American Spine Society. Chronic low back pain. Blue Ridge (IL): North American Spine Society; 2009. Available at:

http://www.knowyourback.org/Pages/Spina 1Conditions/LowBackPain/Acute.aspx. Retrieved on: 2\4\2017

2. Elliott T, Renier C, Palcher J. Chronic pain, depression, and quality of life: correlations and predictive value. Pain Journal 2003; 4 (4): 331-9.

3. Smeltzer S, Bare B, Hinkle J, Cheever K. Brunner\& Suddarth's text book of MedicalSurgical nursing. $12^{\text {th }}$ ed. London: Lippincott Williams \&Wilkins Co. 2010; 503-12.

4. Manchikanti L. Epidemiology of low back pain. Pain Physician Journal 2000; 3(2):167-92.

5. Ramzy S. Etiology and Clinical Presentation of chronic low Back pain. Unpublished Master Thesis, Faculty of Medicine, Alexandria University, 2013.

6. Joseph H, Bredon G, Magaurant J. Geriatric Emergency Medicine: Principles and practice. $2^{\text {nd }}$ ed. United Kingdom: Bridge University Co. 2014; 146-52.

7. Theirs A, Kathleen T. Toward Healthy Aging. China: Mosby Co. 2016; 339-401.

8. Kelley B, Ryan H, Owen R, Gavin V, Eric $\mathrm{S}$, Robert $\mathrm{J}$.The Chronic Low Back Pain Epidemic in Older Adults in America. Pain \& Relief Journal 2017; 6: 285-304.

9. Outpatient clinic statistics of the Physical Medicine, Rheumatology and Rehabilitation Department at the Main University Hospital, Alexandria. 2016.

10. Disoky S, EL-Ghoul Y, Khahed S, Mohamed R. Prevalence of Low Back Pain and its Effect on Quality of Life among Patients Attending Abou Khalefa Center, Ismailia Governorate. Medicine Journal Cairo University 2015; 38 (1): 385-94.

11. Singh M. Decline in lumbar extensor muscle strength in the older adults: correlation with age, gender and spine morphology. Musculoskeletal Disorders Journal 2013; 14(1): 215-20.

12. Jacobs $M$, Rosenberg $R$, Cohen A, Stessman J. Chronic Back Pain among the
Elderly: Prevalence, Associations, and Predictors. Spine Journal 2006; 31(7): 2037.

13. Middleton K, Fish D. Lumbar spondylosis: clinical presentation and treatment approaches. Musculoskeletal Medicine Journal 2009; 2:94-104.

14. Prince M, Guo Y. The burden of disease in older people and implications for health policy and practice. The Lancet Journal 2015; 385: 549-62.

15. Hughes C, Jones F, Brady B. A theoretical and empirical review of psychological factors associated with falls-related psychological concerns in communitydwelling older people. International Psycho geriatrics Journal 2015; 27: 1071-87.

16. Martin R, Hadjistavropoulos T, McCreary D. Fear of pain and fear of falling among younger and older adults with musculoskeletal pain conditions. Pain Research \& Management Journal 2005; 10 : 211-19.

17. Stevens J, Corso P, Finkelstein E, Miller T. The costs of fatal and non-fatal falls among older adults. Injury Prevention Journal 2006; 12(5): 290-5.

18. Hader C, Guy J. Your hand in pain management. Nurs Manag 2004; 35(11)2127. In Daniels $R$, Nosek L, Nicoll L. Contemporary medical-surgical nursing. Philadelphia: Thomson Co. 2007; 447-78.

19. Currie S, Wang J. Chronic back pain and major depression in the general Canadian population. Pain Journal 2004; 107: 54-60.

20. Meyer T, Cooper J, Raspe H. Disabling low back pain and depressive symptoms in the community-dwelling elderly: A prospective study. Spine Journal 2007; 32 (21): 2380-6.

21. Fontoine K. Complementary and alternative therapies for nursing practice. 2nd ed. London: Pearson Prentice Hall Co. 2005; 199-238.

22. Thomas B, Lesley S, Helen E, Diane B. Lewis's Medical-Surgical Nursing: Assessment and management of clinical problems. 4th ed. USA: Elsevier Health Sciences Co. 2015; 243-55.

23. Outpatient clinic statistics of the Physical Medicine, Rheumatology and 
Rehabilitation Department at the Main University Hospital, Alexandria. 2017; from February to April.

24. McGrath P, Seifert C, Speechley K, Booth J, Stitt L, Gibson M. A new analogue scale for assessing children's pain: an initial validation study. Pain Journal 1996; 64 (3):435-43.

25. Tannous S. Effect of slow stroke back massage on motor function, shoulder pain, depression, and anxiety among post -stroke geriatric patients. Unpublished Doctorate dissertation, Faculty of Nursing, Alexandria University, 2015.

26. Cannard G. Falling Trend. Fall risk Journal 1989; 92(2): 36-8.

27. Algameel M. The effect of Tai Chi exercise on balance and fall incidence among institutionalized elderly. Unpublished Doctorate dissertation, Faculty of Nursing, Alexandria University, 2013.

28. Beck A. Development and validation of depression screening scale. Clinical Psychology J1996; 40: 365-67.

29. Podichetty V, Mazanec D, Biscup R. Chronic non-malignant musculoskeletal pain in older adults: clinical issues and opioid intervention. Postgrad Medical Journal 2003; 79: 627-33.

30. Hull S, Farquharson L. Anxiety, Depression, and Fall-Related Psychological Concerns in Community-Dwelling Older People. American Geriatric Psychiatry Journal 2012; 21: 1287-91.

31. Solomon D, Avorn J, Wang P. Prescription Opioid Use among Older Adults with Arthritis or Low Back Pain. Arthritis \&Rheumatism Journal 2006; 55(2): 35-41.

32. Kamada M, Kitayuguchi J, Inoue $\mathrm{S}$, Kamioka H, Abe T, Okada S. Association of low back and knee pain with falls in Japanese community-dwelling older adults: a 3-year prospective cohort study. Geriatric \&Gerontology International Journal 2017; 17(6): 875-84.

33. Marshall M, Richard A, Michael C, Nevitt R. A Prospective Study of Back Pain and Risk of Falls among Older Community-dwelling Women. Gerontology series A Biological Science Journal 2016; 71(9): 1177-83.
34. Nayza M, Daniele S, Leani S. Risk of falls in Brazilian elders with and without low back pain assessed using the Physiological Profile Assessment. Brazilian Journal of physical therapy 2016; 20(6): 502-9.

35. Rudy T, Weiner D, Lieber S, Slaboda J, Boston J. The impact of chronic low back pain on older adults: A comparative study of patients and controls. Pain Journal 2007; 131(3): 293-301.

36. Marcic M, Mihal j, Ivica N, Pintaric I, Titlic M. How severe is depression in low back pain patients. Acta Clinica Croatica (ACC) Journal 2014; 53 (3): 267-71.

37. Tetsunaga $\mathrm{T}$, Misawa $\mathrm{H}$, Tanaka $\mathrm{M}$, Sugimoto Y, Takigawa $\mathrm{T}$. The clinical manifestations of lumbar disease are correlated with self-rating depression scale scores. Orthopedic Science Journal 2013; 18(3): 374-9.

38. Jiménez $\mathrm{S}$, Fernández-de-las-Peñas $\mathrm{C}$, Carrasco-Garrido P, Hernández-Barrera V, Alonso-Blanco C. Prevalence of chronic head, neck and low back pain and associated factors in women residing in the autonomous region of Madrid (Spain). Gaceta Journal 2012; 26: 534-40.

39. Fernandez M, Hartvigsen J, Manuela L, Kathryn M, Paulo H. Chronic low back pain and the risk of depression or anxiety symptoms: insights from a longitudinal study. Spine Journal 2017; 17 (7): 905-12.

40. Fejer R, Ruhe A, Wan S. What is the prevalence of musculoskeletal problems in the elderly population in developed countries? A systematic critical literature review. Chiropractic \& Manual Therapies 2012; 20 (31): 52.

41. Weiner S, Nordin M. Prevention and management of chronic back pain. Best Practice \& Research Clinical Rheumatology Journal 2010; 24: 267-79.

42. Turcu A, Mourey F, Manckoundia P. Falls and depression in older people. Gerontology Journal 2015; 50 (5): 303-8. 